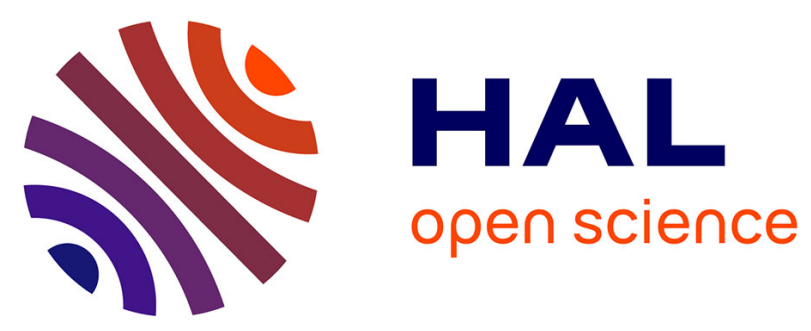

\title{
Fat Grafting for Treatment of Facial Scleroderma
}

Aurélie Daumas, Jeremy Magalon, Flore Delaunay, Maxime Abellan, Cécile

Philandrianos, Florence Sabatier, Brigitte Granel, Guy Magalon

\section{To cite this version:}

Aurélie Daumas, Jeremy Magalon, Flore Delaunay, Maxime Abellan, Cécile Philandrianos, et al.. Fat Grafting for Treatment of Facial Scleroderma. Clinics in Plastic Surgery, 2020, 47 (1), pp.155-163. 10.1016/j.cps.2019.08.016 . hal-03226490

\section{HAL Id: hal-03226490 https://hal-amu.archives-ouvertes.fr/hal-03226490}

Submitted on 17 May 2021

HAL is a multi-disciplinary open access archive for the deposit and dissemination of scientific research documents, whether they are published or not. The documents may come from teaching and research institutions in France or abroad, or from public or private research centers.
L'archive ouverte pluridisciplinaire HAL, est destinée au dépôt et à la diffusion de documents scientifiques de niveau recherche, publiés ou non, émanant des établissements d'enseignement et de recherche français ou étrangers, des laboratoires publics ou privés. 


\section{Fat Grafting for Treatment of Facial Scleroderma}

Aurélie Daumas $^{\text {a,e }}$, Jeremy Magalon ${ }^{\text {bee }}$, Flore Delaunay ${ }^{\text {c,e }}$, Maxime Abellan ${ }^{\text {d,e }}$, Cécile Philandrianos $^{\text {d,e }}$, Florence Sabatier ${ }^{\text {b,e }}$, Brigitte Granel ${ }^{\text {a,e }}$, Guy Magalon d,e

a Internal Medicine Department, Assistance Publique Hôpitaux de Marseille (AP-HM), Aix-Marseille University, FRANCE: Professor B Granel MD, A Daumas MD

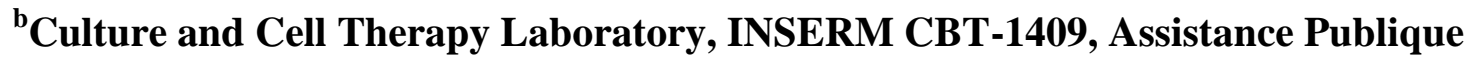
Hôpitaux de Marseille (AP-HM), Aix-Marseille University, FRANCE: Professor F Sabatier Pharm D, Professor G Magalon MD, J Magalon Pharm D

${ }^{c}$ Plastic Surgery Department, Centre Hospitalier du Belvédère, Mont Saint Aignan FRANCE: Flore Delaunay MD

d Plastic Surgery Department, Assistance Publique Hôpitaux de Marseille (AP-HM), Aix-Marseille University, FRANCE: Professor G Magalon MD, C Philandrianos MD, M Abellan MD

${ }^{\text {e }}$ Aix-Marseille University, FRANCE: Professor F Sabatier Pharm D, Professor B Granel MD, A Daumas MD, J Magalon Pharm D

E-mail addresses :

aurelie.daumas@ap-hm.fr, $\quad$ jeremy.magalon@ap-hm.fr, flore.delaunay@yahoo.fr, maxime.abellan@ap-hm.fr, cecile.philandrianos@ap-hm.fr, florence.sabatier@ap-hm.fr, bgranel@ap-hm.fr, secretariat.magalon@gmail.com

Aurélie Daumas and Jérémy Magalon contribued equally to this work

\section{Correspondence:}

Professor Guy MAGALON, MD

Conception Hospital,

Assistance Publique Hôpitaux de Marseille (AP-HM)

139015 Marseille FRANCE

Phone: 33614268109 , 
Fax: 33491388717 ,

e-mail: secretariat.magalon@gmail.com

Author Disclosure :

Guy MAGALON has the following potential conflicts of interest to report:

- Consultant for the Thiebaud Medical Device

- Financial grants and other support for Research and honorarium as consultant 


\section{Keywords}

Systemic sclerosis, cell therapy, micro-fat injection, nanofat, platelet-rich plasma, stromal vascular fraction, fat grafting, autologous fat graft, adipose tissue

\section{Synopsis}

Grafted fat exhibits many of the qualities of ideal filler. It is autologous, easily available in most patients, and naturally integrated into the host tissues. From a lipoaspirate, the adipose tissue-derived stromal vascular fraction can be isolated which contains an excellent source of stem/stromal cells, endothelial progenitors and immune cells. Reparative, angiogenic and immunomodulatory properties have been recognized to the cells inside the adipose tissuederived stromal vascular fraction. Because of these characteristics, in the last decade fat grafting has become increasingly popular in aesthetic and reconstructive surgery. Its application in autoimmune diseases is growing and we focus this article on systemic sclerosis, a rare autoimmune disease characterized by skin fibrosis and microvascular damage. Lesions of the face are almost always present, however, current therapy is insufficient and patients have a great disability and social discomfort. We present our approach using fat graft in the face as innovative and promising therapy for systemic sclerosis patients.

\section{Key points}

- Systemic sclerosis is a rare autoimmune disease characterized by skin fibrosis,microvascular damage and organs dysfunction

- Facial signs are frequent and include perioral skin thickening, facial atrophy and microstomia

- Facial manifestations are disfiguring and lead to social disability with psychological distress 
- Autologous fat tissue grafting has emerged as a treatment of localized scleroderma and patients with SSc-related perioral thickening and mouth opening limitation

- Cell-based strategies to enrich fat grafts is a promising option in regenerative medicine

One surgical technique video accompanies this article, showing the author's approach to surgery of the face in systemic sclerosis patients.

\section{INTRODUCTION}

Systemic sclerosis ( $\mathrm{SSc}$ ) is a chronic systemic autoimmune disease characterized by progressive skin and internal organ fibrosis, microvascular abnormalities and autoimmune ${ }^{1}$ Life-threatening organ lesions leading to pulmonary arterial hypertension, pulmonary fibrosis, and scleroderma renal crisis only affect a minority of patients. By contrast, lesions of the hands and face are almost always present. Although not life-threatening, these manifestations are very obvious, hard to conceal, and lead to disability and worsening quality of life. ${ }^{2-4}$ Facial symptoms are associated with cosmetic disfigurement and limited expression with mask-like stiffness of the face. No anti-fibrotic treatment has proven effective. Unlike other autoimmune diseases, immunosuppressive drugs have a limited clinical interest. ${ }^{5,6}$ Thus, improvement of face motion and appearance represent a real challenge for physicians and a priority for patients who often feel that this aspect of their disease is neglected.

Utilization of adipose tissue as filling product in plastic and aesthetic surgery is an ancient technique. Significant renewal of interest in this approach for the restoration of all volume defects was observed after the description of the Lipostructure ${ }^{\circledR}$ technique by Coleman. ${ }^{7}$ Autologous fat transplantation became the first choice technique to hide cutaneous 
lesions; this approach, using the patient's own body fat as a natural filler to achieve structural modifications, take advantage of its abundance and accessibility. Elective liposuction for fat transplantation is nowadays considered a safe and well-tolerated procedure. Recently, identification and characterization of the adipose tissue-derived stromal vascular fraction (AD-SVF), a population that includes mesenchymal stem cell-like cells, endothelial progenitor cells, and haematopoietic cells, have revolutionized the science showing that adipose tissue is a valuable source of cells with multipotency, angiogenic and immunomodulatory properties that facilitate tissue repair. ${ }^{8-13}$ In SSc, the Coleman lipostructure $^{\circledR}$ technique is not adapted because instruments do not enable direct fat grafting at a subdermic level nor in layers that are poorly extensible or fibrotic. Currently, microfat grafting described by Nguyen et al. $^{14}$ consisting of harvesting fat tissue using a multiperforated cannula with holes of $1 \mathrm{~mm}$ allows to harvest smaller lobules of fat (around $600 \mu \mathrm{m})$ particularly useful when restoring soft facial tissue. ${ }^{15}$ We previously reported an improvement of facial handicap in 14 patients suffering from SSc after autologous perioral microfat injection. ${ }^{16}$ However, the clinical success of fat grafting is limited by its variable and unpredictable local survival rate. One of the most developments in recent years is the use of pro-survival strategies to improve maintenance of fat volume and trophicity.

Recently, plastic surgeons have added Platelet-Rich Plasma (PRP) to injected fat hypothesizing that growth factors produced in vivo would enhance the neovascularization, proliferation, and differentiation of adipose stem cells, improving patient outcomes. ${ }^{17-19}$ More recently, skin regenerative potential of nanofat grafting was studied by Tonnard et al. ${ }^{20}$ The process consists in mechanical emulsification by manually repeatedly shifting the fat between two 10-mL connected syringes and final filtering of the lipoaspirate to obtain a loose, homogeneous liquid suspension, defined as "nanofat", which can be directly administered to 
patients for regenerative purposes via very small needles. ${ }^{21}$ As the obtained product does not meet the true dimensions required as "nano" sizes, the term emulsified fat is more accurate.

We present herein our clinical approach using microfat and emulsified fat (nanofat) enriched in PRP in the treatment of the face in patients with SSc.

\section{PATHOLOGY OF SCLERODERMA}

Involvement of the face with associated oral complications, aesthetic changes, and impairment of the patient's self-image, is found in over $90 \%$ of patients with $\mathrm{SSc}^{3}$

Table 1 and Fig. 1 illustrate the main orofacial findings in patients with SSc.

Facial involvement is associated with disfigurement and limited expression with a mask-like stiffness of the face. The loss of elasticity and the thickening of the skin in the perioral area and lips form perioral radial furrowing and narrowing of the oral aperture, leading to mouth opening reduction that interferes considerably with life's basic functions such as eating, speaking, oral hygiene, and professional dental care. Furthermore, dry mouth or xerostomia because of salivary gland fibrosis and reduced saliva production increase the risk of periodontal diseases and caries. ${ }^{3,22,23}$

Table 1: Orofacial findings in patients with SSc

\begin{tabular}{|l|l|}
\hline Orofacial findings & Commentaries \\
\hline Skin sclerosis of the face & $\begin{array}{l}\text { Very frequent, around 90\% of cases. The face becomes } \\
\text { amimic, cutaneous wrinkles disappear, vertical furrows } \\
\text { develop around the mouth due to retraction of the skin, the } \\
\text { nose becomes sharp and lips thin. }\end{array}$ \\
\hline Telangiectasia & Especially located in the face, lips or the inside of the \\
\hline
\end{tabular}




\begin{tabular}{|c|c|}
\hline & mouth, they can lead to severe aesthetic concerns. \\
\hline $\begin{array}{l}\text { Skin pigmentation } \\
\text { abnormalities }\end{array}$ & $\begin{array}{l}\text { Hypopigmentation and hyperpigmentation mostly observed } \\
\text { in the diffuse cutaneous form of scleroderma. Vitiligo is } \\
\text { possible. }\end{array}$ \\
\hline Sicca syndrome & $\begin{array}{l}\text { Sicca syndrome is detected in approximately } 70 \% \text { of } \\
\text { patients with SSc. It is secondary to salivary gland fibrosis. }\end{array}$ \\
\hline Diminished mouth opening & $\begin{array}{l}\text { Frequent, around } 60 \% \text {. Thinning of lips and reduction of } \\
\text { mouth width (microcheilia) and opening (microstomia) with } \\
\text { as consequence difficult dental cares. }\end{array}$ \\
\hline $\begin{array}{l}\text { Osteolysis of mandibular } \\
\text { angles }\end{array}$ & $\begin{array}{l}\text { Mandibular bone resorption is mainly encountered in } \\
\text { patients with marked facial skin fibrosis: chewing and } \\
\text { swallowing movements may be impaired, pain if often } \\
\text { reported. }\end{array}$ \\
\hline $\begin{array}{l}\text { Altered dentition and } \\
\text { difficulties during dental } \\
\text { care }\end{array}$ & $\begin{array}{l}\text { Oromucosal involvement include ulcerations, dry mouth, } \\
\text { periodontitis, wide periodontal ligament space, dental root } \\
\text { resorption and loose teeth. }\end{array}$ \\
\hline
\end{tabular}

Figure 1: Various aspects of SSc face involvement showing skin sclerosis, cutaneous wrinkles, vertical furrows develop around the mouth, sharp nose and lip retraction, telangiectasia hypopigmentation and hyperpigmentation and reduction of mouth opening 


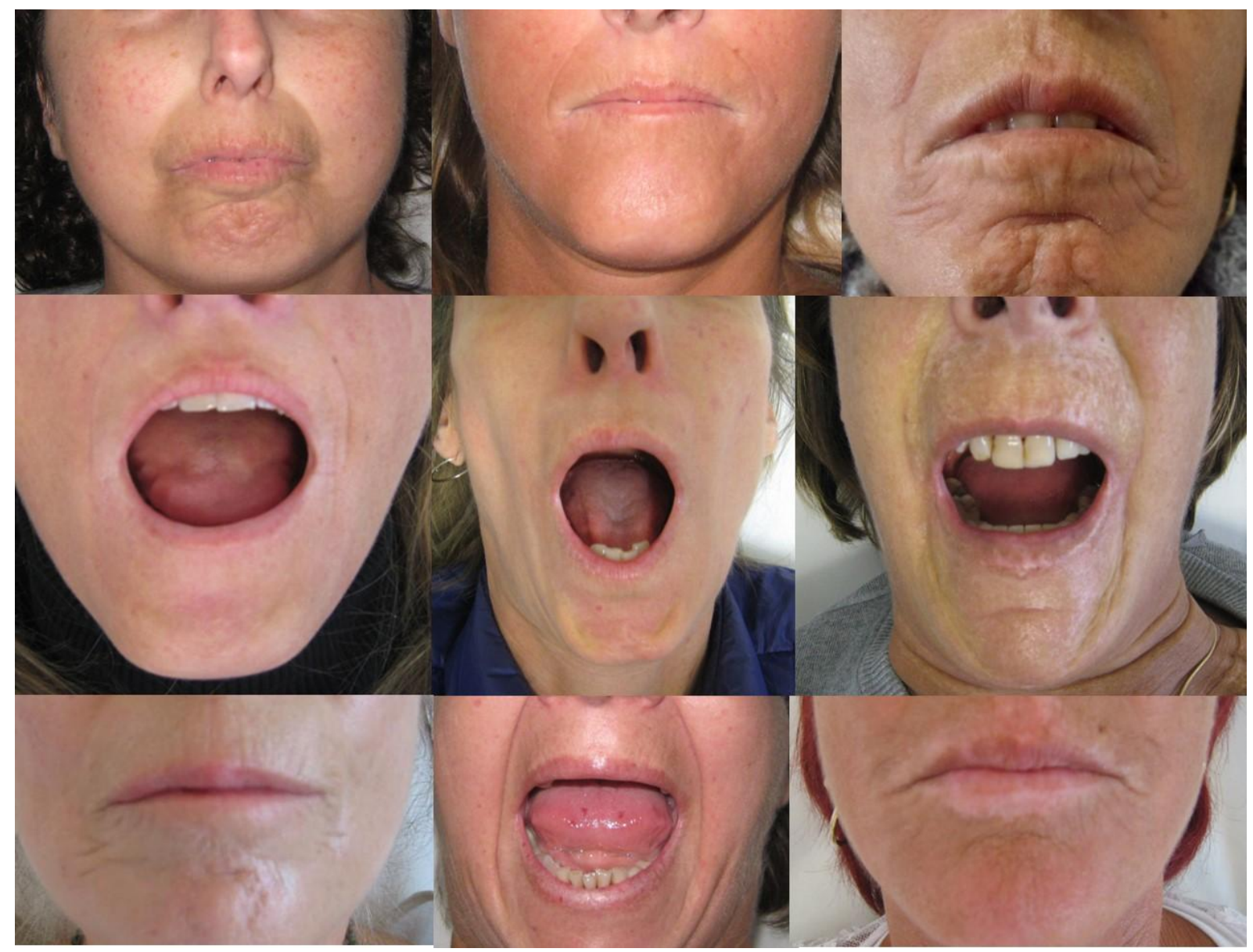

Several validated tools have been developed for assessment of the involvement of the face. Skin involvement is usually assessed by the Rodnan skin score. This semi-quantitative score rates the severity of skin sclerosis from 0 (normal) to 3 (most severe). Xerostomia can be easily measured by sugar test (time to melt a sugar on the language, without crunching it) and with the Xerostomia Inventory Index. Mouth opening is assessed in centimeters by measuring the distance between the tips of upper and lower incisive teeth. Elastosonography and 3D photographs can also be used. Mouth-related disability can be assessed by the MHISS (Mouth Handicap in Systemic Sclerosis) scale which is the first mouth-specific disability outcome measure designed for SSc patients. ${ }^{3}$ This scale evaluates three factors: reduced mouth opening, sicca syndrome and aesthetic concerns. Although mouth disability appears to have less weight than hand disability in total disability, the MHISS score explained up to $36 \%$ of 
the variance of the HAQ (Heath Assessment Questionnaire) score. This highlights the need to specifically assess disability involving the mouth in patients with SSc. Rehabilitation and management of face is mainly based on physiotherapy with mimic exercises, massage, and self-administered home-based exercises. Mouth and dental care are not specific.

Some case-reports have shown the efficacy of autologous fat grafting in the treatment of linear scleroderma. ${ }^{24,25}$ Besides the volumizing effect of mechanical lipofilling, autologous fat grafting contains various cells such as adipose-derived stem/stromal cells, endothelial progenitor cells and immune cells which act together for trophic and angiogenic effects. The use of autologous grafting of adipose tissue appears to have substantial potential to correct signs of face involvement in SSc.

\section{SURGICAL TECHNIQUE USING MICROFAT AND EMULSIFIED FAT}

\section{ENRICHED PRP}

Reinjection of autologous fat tissue has volumizing and trophic properties. Coleman formalised the technique and nowadays, most surgeons consider adipose tissue to be the ideal filler. However, the special context of SSc requires certain modifications to this approach, in particular, the use of harvest and implantation of smaller morsels or packets of adipose tissue. ${ }^{14}$ Thus, microfat grafting has been a first evolution of the art. This minimally invasive technique is now enriched with PRP, which contains high amount of growth factors to improve microfat retention. Treatment of face disability of SSc patients is currently completed with emulsified fat enriched with PRP for regenerative purposes presenting the advantage to go through smaller needles (from 25 to 30-gauge). (Video 1 Treatment of Scleroderma injuries of the face using a mixture of Microfat - Emulsified fat and PRP). 


\section{Patient selection}

During the first consultation (after a clinical and photographic analysis), the surgeon checks the venous access for blood harvesting and defines the amount of adipose tissue necessary and the areas from which this tissue can be harvested. Preferred harvesting areas include the inner side of the knees, abdomen, external thigh, internal thigh, back. The most preferred location for small quantities is the inner side of the knees. In case of previous adipose tissue harvesting or cryolipolysis, a non-treated area should be preferred to avoid any fibrosis tissue. The entire procedure takes place under local anaesthesia (supplemented with conscious sedation if needed) and can be performed either as an outpatient or inpatient care.

\section{Preparation of Platelet Rich Plasma}

After skin disinfection, a nurse collected $18 \mathrm{~mL}$ of blood by venipuncture using a 21-gauge needle filling one 20-mL syringe containing $2 \mathrm{~mL}$ of ACD-A (Fidia, Abano Terme, Italy) (Figure 2A). The blood was transferred into the Hy-tissue 20 PRP device (Fidia, Abano Terme, Italy) before centrifugation at $3200 \mathrm{rpm}$ during 10 minutes using the Omnigrafter 2.0 (Fidia, Abano Terme, Italy). $9.1 \mathrm{~mL}$ of PRP was recovered using a 10-mL syringe through the Push-out system (Figure 2B,C). $300 \mu \mathrm{L}$ of whole blood and autologous PRP preparation were sampled to determine platelets, leukocytes and RBCs concentrations according recent guidelines. $^{26}$

\section{Infiltration and Microfat sampling}

The first step is anaesthesia of the entry points with a small syringe and a 30-gauge needle with pure lidocaine $1 \%$ and epinephrine $(1 \mathrm{mg} / \mathrm{L})$ to avoid bleeding. For infiltration of the harvested area, we use a modified Klein solution of lidocaine $1 \%$ and epinephrine $(1 \mathrm{mg} / \mathrm{L})$. 
The microfat harvesting technique was performed using a Hapifat ${ }^{\circledR}$ kit (Benew Medical, Melesse, France). Entry points are made with a 14-gauge needle, before inserting the infiltration/harvesting St'rim cannula (14-gauge, $2 \mathrm{~mm}$ external diameter, 8 holes of $0.58 \mathrm{~mm}$ square). Infiltration is performed in a closed system between bag containing anaesthetic solution and cannula using the three-way valve Fat Lock System® (yellow) (Figure 2D). Diffusion of the anaesthetic solution during 10 minutes before microfat harvesting is recommended. Microfat is harvested with the same St'rim cannula both connected to a $10-\mathrm{mL}$ syringe and a purification Puregraft $50 \AA$ bag through a Fat Lock System ${ }^{\circledR}$ (red) under low vacuum keeping the plunger in contact with the fat (Figure 2E). Approximatively $45 \mathrm{~mL}$ of microfat was collected (Figure 2F).

\section{Purification and preparation of Microfat}

Microfat was then purified two times using 1:1 rinsing with saline solution allowing for the elimination of fluid excess, lipid phase, blood cells, and fragments through filtration by the Puregraft bag membrane. Approximatively $17 \mathrm{~mL}$ of purified microfat was obtained. $8 \mathrm{~mL}$ is transferred via a Luer Lock connector in 10-mL syringe (Figure 2I).

\section{From Microfat to Emulsified fat}

Remaining $8.6 \mathrm{~mL}$ of microfat were emulsified using Tulip Nanofat device (Tulip, San Diego, CA, USA). Microfat was emulsified between two $10-\mathrm{mL}$ syringes connected with $2.4 \mathrm{~mm}$ connector (30 passes) and $1.2 \mathrm{~mm}$ (30 passes) (Figure 2J). Emulsified fat is then filtered through the device $(629 \mu \mathrm{m}$ and $394 \mu \mathrm{m})$ to remove extracellular matrix fibers (Figure $2 \mathrm{~K}$ ). $7.8 \mathrm{~mL}$ of emulsified fat were transferred in a $10-\mathrm{mL}$ syringe (Figure $2 \mathrm{~L}$ ).

\section{Mixed Products}


Microfat was mixed with PRP in a $80 / 20$ proportion using two 10 -mL syringes connected. Mixed product has to be immediately transferred in 1-mL syringe before injection. After microfat/PRP mix injection, the emulsified fat is mixed with PRP in the same way (Figure $2 \mathrm{M}, \mathrm{N})$.

\section{Placement}

The entry points are anesthetized with pure lidocaine $1 \%$ and epinephrine $(1 \mathrm{mg} / \mathrm{L})$ using a 30 -gauge needle. The skin barrier is crossed with a 21 -gauge needle in the same direction in which we want to introduce microfat through the placement cannula (21-gauge, $0.8 \mathrm{~mm}, 40$ mm length). In this case, microfat-PRP mixture was injected in cheekbones, nasolabial folds, and chin for a volumizing effect. Regarding emulsified fat-PRP mixture, the placement is performed using the same procedure but with a 25-gauge needle. This is dedicated to area where regenerative and trophic effects are targeted instead of volumizing one. In this case, it was injected in upper lip, lower lip and sub mucosal at the level of the oral commissure. Tissue may be injected in all areas, but especially in the superficial plane, as close to the skin level as can be achieved without risk of irregularities that could be corrected by a gentle massage.

\section{Postoperative period}

Postoperative course is extremely simple. There are no painful symptoms, the swelling is extremely small and there is normally little bruising. The result is stable following the second postoperative month. An improvement in the quality of skin, aesthetic appearance, face pain and mouth opening can be observed. 


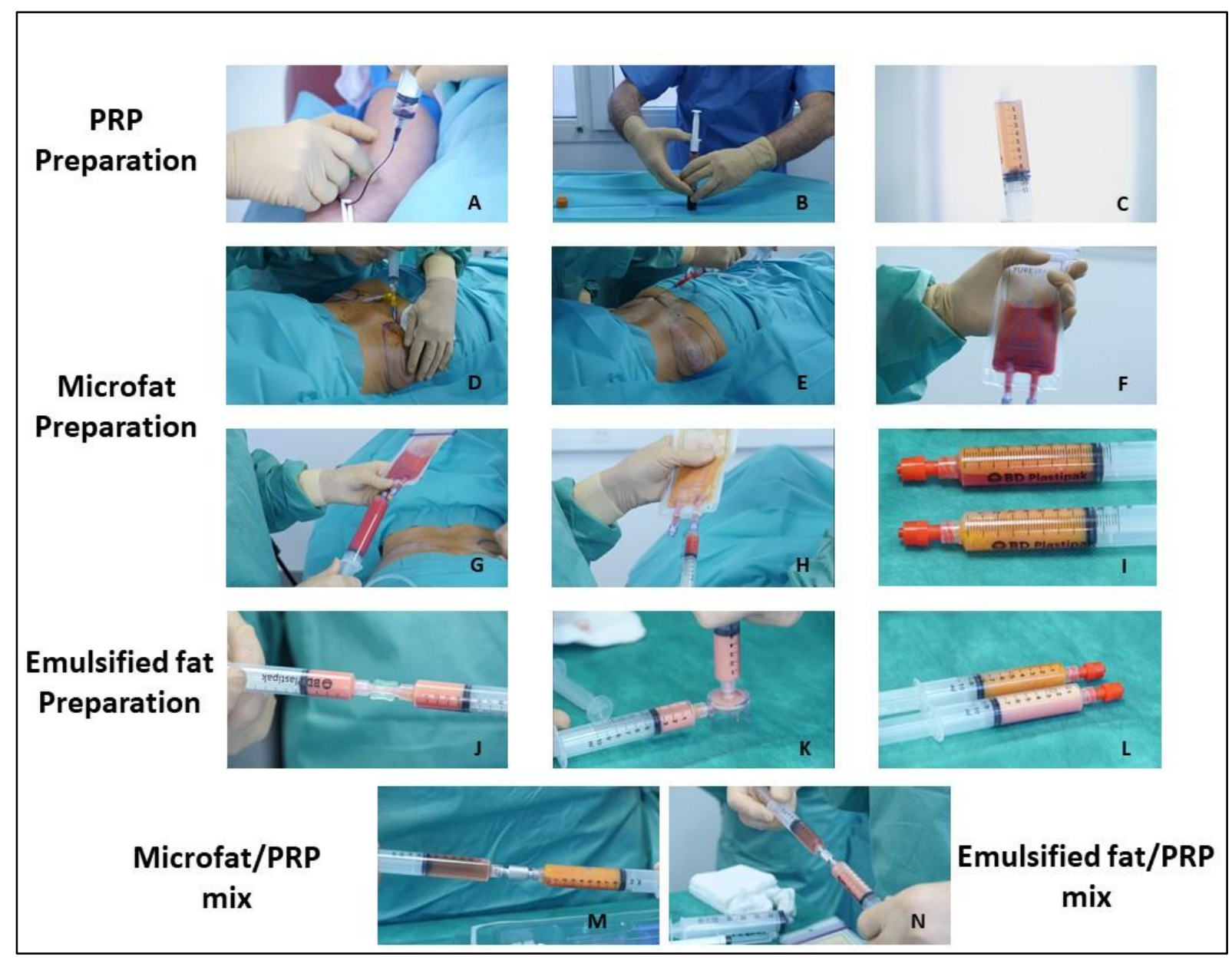

Figure 2: Preparation of the regenerative products for facial disability treatment of SSc patients
A. Aseptic harvesting of the blood
B. Preparation of PRP
C. Final aspect of PRP
D. Anaesthetic infiltration of harvesting area
E. Harvesting of microfat in closed system
F. Aspect of microfat harvesting before washing
G. Washing step of microfat
H. Recovery of microfat
I. Final aspect of microfat
J. Emulsification step of microfat (through $1.2 \mathrm{~mm}$ connector)
K. Filtration step of emulsified fat
L. Final aspect of microfat (orange) and emulsified fat (pink)
M. Mixing step of microfat and PRP in $80 / 20$ proportion
N. Mixing step of emulsified fat and PRP in 80/20 proportion

\section{Case Demonstration}


A 50-year old woman suffering from SSc consulted for functional and cosmetic improvement of her face. SSc was diagnosed in 2009 and was characterized by skin sclerosis under her forearm (limited cutaneous form of the disease), Raynaud's phenomenon and upper digestive symptoms with typical pattern of oesophagus involvement at manometry. She did not suffer from pulmonary arterial hypertension, interstitial lung disease or renal crisis. She was taking esomeprazole and emollient creams on her face twice a day. Her medical history did not include any other disease, alcohol or smoking. Biological investigations showed positive anticentromere antibodies, with normal blood tests, renal and liver function tests and no iron, or B12 and B9 vitamins deficiency. Her physical examination revealed marked skin thickening on the face with a Rodnan skin score applied to face at $2 / 3$. At entry, MHISS score was at $31 / 48$ and mouth opening at $25 \mathrm{~mm}$. According to the surgical procedure described above, 9.6 $\mathrm{mL}$ of microfat-PRP mixture was injected in cheekbones, nasolabial folds, and chin for a volumizing effect and $9.4 \mathrm{~mL}$ of emulsified fat-PRP mixture in upper lip, lower lip and sub mucosal at the level of the oral commissure for regenerative and trophic effects (Figure 3). No specific medication was given after the treatment except for mild analgesics. Tolerance was good and when asked 10 days later, the patient declared to be very satisfied.

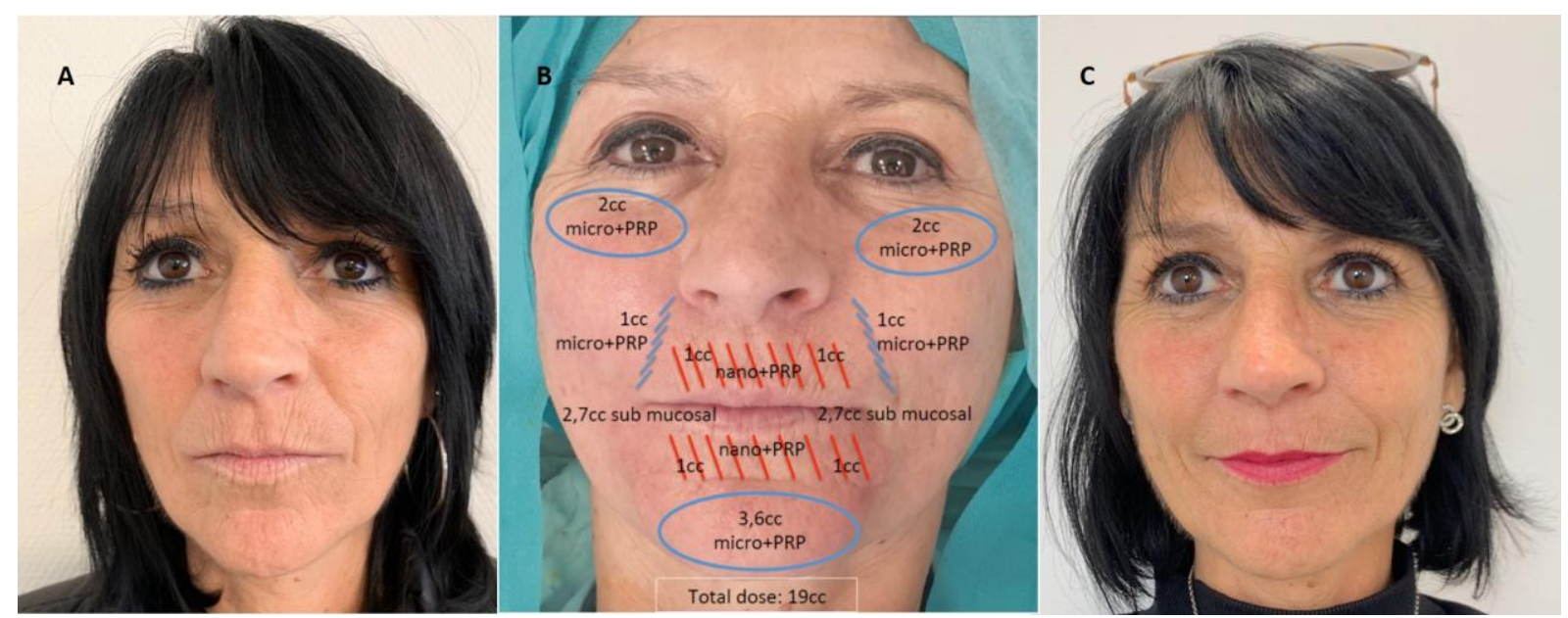

Figure 3. Systemic sclerosis patient face

\section{A. Pre-operative regenerative treatment}




\section{B. Regenerative products placement and quantities \\ C. 10 days post-operative regenerative treatment}

\section{DISCUSSION}

Facial handicap in SSc patients is often overlooked, but it is highly important for the patient's quality of life, and therapeutic approaches are lacking.

In recent decades, autologous adipose tissue grafting has been successfully used to treat number of clinical conditions characterized by skin atrophy or fibrosis such as radiodermitis, burning sequelae but also patients affected by linear scleroderma and morphea. In most of these cases, both aesthetic and functional improvement has been reported with no serious side effects.

We carried out an open-label, single-arm, monocentric trial among 14 patients (mean age of $53.8 \pm 9.6$ years) suffering from SSc with facial handicap defined by MHISS score more than or equal to 20 , a Rodnan skin score on the face more than or equal to 1 , and maximal mouth opening of less than $55 \mathrm{~mm} .{ }^{16}$ Autologous adipose tissue injection was performed under local anesthesia using the technique of subcutaneous microinjection. We observed a mean decrease in the MHISS score of 10.7 points $( \pm 5.1 ; P<0.0001)$ at 6 months (35\% improvement). Secondary efficacy parameters assessing perioral skin sclerosis, maximum mouth opening, sicca syndrome, and facial pain significantly improved at 3 and 6 months postsurgery. At a 6month follow-up, $75 \%$ of patients were satisfied or very satisfied of the adipose tissue microinjection therapy. Del Papa et al. ${ }^{27}$ also reported a significant clinical improvement in oral opening in 20 patients with SSc using the Coleman method. This study showed safety and feasibility of a different surgical procedure and a significant improvement of the mouth opening capacity after perioral fat grafting, with a benefit obtained as early as 3 months after the procedure. In comparison with our study, a similar mean quantity of purified fat reinjection was performed $(16 \mathrm{ml})$, and the statistically significant increase of the maximum 
interincisive distance at 3 months in the study by Del Papa et al. was very close to the one observed in our study. But now the time is up to cell mixes to improve skin trophicity and enhance fat graft survival.

Platelet-rich plasma (PRP) consists of a gel fraction obtained from peripheral blood. PRP is described as having a role in increasing fat graft survival by providing nutrient support from its plasma component and enhancing the proliferation of pre-adipocytes through the secretion of a great variety of growth factors and cytokines. In a recent trial, Virzi et al. ${ }^{28}$ demonstrated the beneficial effects of the combined use of autologous lipoaspirate and PRP in the improvement of the buccal rhyme, skin elasticity, and vascularization of the perioral and malar areas of patients with SSc. One of the main weakness in PRP field remains the high heterogeneity from a preparation to another that could influence clinical outcome. ${ }^{29}$ This leads to contradictory results in preclinical studies that have assessed the impact of PRP on graft survival. ${ }^{30,31}$ The microfat-PRP mixture described in our case was previously validated on two aspects: i) from a rheological point of view where a $80 / 20$ proportion mixture correspond to a soft product ${ }^{32}$; ii) regarding the PRP quality, the selected device furnishes a pure PRP (>90\% platelets in the final product compared to red blood cells and leukocytes) ${ }^{33}$ and the final mixture contains around 100 millions of platelets $/ \mathrm{ml}$ of mix. This latter point seems important at the light of the recently reported results by Willemsen et al. ${ }^{34}$ in a double-blinded, placebocontrolled randomized trial that compared the use of fat alone vs. a fat-PRP mix for facial rejuvenation. In this study, PRP did not improve outcomes in terms of skin elasticity or graft volume maintenance. Unfortunately, the report does not detail either the volume or biological characteristics of the injected PRP, but authors suggested that high platelet levels may be counterproductive, possibly because they trigger undesirable cellular differentiation or ASC differentiation toward a fibroblast-like phenotype. 
One of the novelty described in this clinical case is the use of nanofat. The term "nanofat" was introduced by Tonnard et al. ${ }^{20}$ describing a new method to prepare autologous fat in order to predominantly make use of its regenerative properties. They demonstrated that no viable adipocytes were left after the emulsification process, but nanofat contains a large amount of adipose stem cells and stromal vascular components. Nanofat is not suitable for filling up soft tissue defects. It can be applied as a superficial intradermal filler but the main clinical application of nanofat is to stimulate tissue regeneration and remodeling. This safe and feasible application makes it a valuable new tool in SSc. We decided to mix nanofat with the

PRP based on the recent preclinical results of Lei and al. ${ }^{35}$ describing a high degree of angiogenesis and better survival with nanofat-PRP mixture. Although the PRP/nanofat treatment in association with microfat is promising, the optimal nanofat-to-PRP ratio still need to be explored.

\section{Conclusion}

The current trend is to mix adipose cell-based therapies to improve facial disability by both volumizing and regenerative effects. Despite encouraging results and patient's satisfaction, the standardization of mixture preparation and treatment methods is a pressing issue and controlled studies are essential to estimate the positive effect to PRP and nanofat to microfat. 


\section{REFERENCES}

1. Servettaz A, Agard C, Tamby MC et al. Systemic sclerosis: pathophysiology of a multifaceted disease. Presse Med 2006;35:1903-15.

2. Maddali Bongi S, Del Rosso A, Mikhaylova S et al. Impact of hand and face disabilities on global disability and quality of life in systemic sclerosis patients. Clin Exp Rheumatol 2014;32:S15-20.

3. Mouthon L, Rannou F, Bérezné A, et al., Development and validation of a scale for mouth handicap in systemic sclerosis: the Mouth Handicap in Systemic Sclerosis scale. Ann Rheum Dis 2007;66:1651-5.

4. Rannou F, Poiraudeau S, Berezné A, et al. Assessing disability and quality of life in systemic sclerosis: construct validities of the Cochin Hand Function Scale, Health Assessment Questionnaire (HAQ), Systemic Sclerosis HAQ, and Medical Outcomes Study 36-Item Short Form Health Survey. Arthritis Rheum 2007;57:94-102.

5. Kowal-Bielecka O, Landewé R, Avouac J, et al. EULAR recommendations for the treatment of systemic sclerosis: a report from the EULAR Scleroderma Trials and Research group (EUSTAR). Ann Rheum Dis 2009;68:620-8.

6. Pope JE, Bellamy N, Seibold JR, et al. A randomized, controlled trial of methotrexate versus placebo in early diffuse scleroderma. Arthritis Rheum 2001;44:1351-8.

7. Coleman, S.R., Structural fat grafting: more than a permanent filler. Plast Reconstr Surg 2006;118:108S-120S.

8. Gimble, J.M., A.J. Katz, and B.A. Bunnell, Adipose-derived stem cells for regenerative medicine. Circ Res 2007;100:1249-60.

9. Zuk PA, Zhu M, Ashjian P, et al. Human adipose tissue is a source of multipotent stem cells. Mol Biol Cell 2002;13:4279-95.

10. Kapur SK, Katz AJ. Review of the adipose derived stem cell secretome. Biochimie. 2013;95:2222-8.

11. Leto Barone AA, Khalifian S, Lee WP, et al. Immunomodulatory effects of adiposederived stem cells: fact or fiction?. Biomed Res Int 2013;2013:383685.

12. Rehman J, Traktuev D, Li J, et al. Secretion of angiogenic and antiapoptotic factors by human adipose stromal cells. Circulation 2004;109:1292-8. 
13. Scuderi N, Ceccarelli S, Onesti MG, et al. Human adipose-derived stromal cells for cell-based therapies in the treatment of systemic sclerosis. Cell Transplant 2013;22:779-95.

14. Nguyen PS, Desouches C, Gay AM, et al. Development of micro-injection as an innovative autologous fat graft technique: The use of adipose tissue as dermal filler. $\mathrm{J}$ Plast Reconstr Aesthet Surg 2012;65:1692-9.

15. Alharbi Z, Opländer C,Almakadi S, et al. Conventional vs. micro-fat harvesting: how fat harvesting technique affects tissue-engineering approaches using adipose tissuederived stem/stromal cells. J Plast Reconstr Aesthet Surg 2013;66:1271-8.

16. Sautereau N, Daumas A, Truillet R,et al. Efficacy of Autologous Microfat Graft on Facial Handicap in Systemic Sclerosis Patients. Plast Reconstr Surg Glob Open 2016;4:e660.

17. Luck J, Smith OJ, Mosahebi A. A Systematic Review of Autologous Platelet-Rich Plasma and Fat Graft Preparation Methods. Plast Reconstr Surg Glob Open 2017;5:e1596.

18. Serra-Mestre JM, Serra-Renom JM, Martinez L, et al. Platelet-rich plasma mixed-fat grafting: a reasonable prosurvival strategy for fat grafts ? Aesthetic Plast Surg 2014;38:1041-9.

19. Jin R, Zhang L, Zhang Y-G. Does platelet-rich plasma enhance the survival of grafted fat ? An update review. Int J Clin Exp Med 2013;6:252-8.

20. Tonnard P, Verpaele A, Peeters G, et al. Nanofat grafting: basic research and clinical applications. Plast Reconstr Surg 2013;132:1017-26.

21. Alexander RW. Understanding mechanical emulsification (Nanofat) versus enzymatic isolation of tissue stromal vascular fraction (tSVF) cells from adipose tissue: Potential uses in biocellular regenerative medicine. J Prolotherapy 2016;8:e947-e960.

22. Wood, R.E. and P. Lee, Analysis of the oral manifestations of systemic sclerosis (scleroderma). Oral Surg Oral Med Oral Pathol 1988;65:172-8.

23. Vincent C, Agard C, Barbarot S et al., Orofacial manifestations of systemic sclerosis: a study of 30 consecutive patients. Rev Med Interne 2009;30:5-11.

24. Oh, C.K., et al., Treatment of atrophies secondary to trilinear scleroderma en coup de sabre by autologous tissue cocktail injection. Dermatol Surg 2003;29:1073-5. 
25. Consorti, G., R. Tieghi, and L.C. Clauser, Frontal linear scleroderma: long-term result in volumetric restoration of the fronto-orbital area by structural fat grafting. $\mathrm{J}$ Craniofac Surg 2012;23:263-5.

26. Graiet H, Lokchine A, Francois P, et al. Use of platelet-rich plasma in regenerative medicine: technical tools for correct quality control. BMJ Open Sport Exerc Med 2018;4:e000442.

27. Del Papa N, Caviggioli F, Sambataro D, et al. Autologous fat grafting in the treatment of fibrotic perioral changes in patients with systemic sclerosis. Cell Transplant 2015;24:63-72.

28. Virzì F, Bianca P, Giammona Aet al. Combined platelet-rich plasma and lipofilling treatment provides great improvement in facial skin-induced lesion regeneration for scleroderma patients. Stem Cell Res Ther 2017;8:236.

29. Magalon J, Bausset O, Serratrice N, et al. Characterization and comparison of 5 platelet-rich plasma preparations in a single-donor model. Arthrosc J Arthrosc Relat Surg Off Publ Arthrosc Assoc N Am Int Arthrosc Assoc 2014;30:629-38.

30. Nakamura S, Ishihara M, Takikawa M, et al. Platelet-rich plasma (PRP) promotes survival of fat-grafts in rats. Ann Plast Surg 2010;65:101-6.

31. Por Y-C, Yeow VK-L, Louri Net al. Platelet-rich plasma has no effect on increasing free fat graft survival in the nude mouse. J Plast Reconstr Aesthetic Surg 2009;62:1030-34.

32. Ghazouane R, Bertrand B, Philandrianos C, et al. What About the Rheological Properties of PRP/Microfat Mixtures in Fat Grafting Procedure? Aesthetic Plast Surg 2017;41:1217-21.

33. Guillibert C, Charpin C, Raffray M,et al. Single Injection of High Volume of Autologous Pure PRP Provides a Significant Improvement in Knee Osteoarthritis: A Prospective Routine Care Study. Int J Mol Sci 2019;15;20.

34. Willemsen JCN, Van Dongen J, Spiekman M, et al. The Addition of Platelet-Rich Plasma to Facial Lipofilling: A Double-Blind, Placebo-Controlled, Randomized Trial. Plast Reconstr Surg 2018;141:331-343. 
35. Tonnard P, Verpaele A, Peeters G, et al. Nanofat grafting: basic research and clinical applications. Plast Reconstr Surg 2013;132:1017-26.

36. Lei X, Liu H, Pang $M$, et al. Effects of Platelet-Rich Plasma on Fat and Nanofat Survival: An Experimental Study on Mice. Aesthetic Plast Surg 2019 [Epub ahead of print] 